\title{
Review of seasonal forecasting in South Africa: producer to end-user
}

\author{
P. A. Johnston ${ }^{1, *}$, E. R. M. Archer ${ }^{1}$, C. H. Vogel $^{2}$, C. N. Bezuidenhout ${ }^{3}$, \\ W. J. Tennant ${ }^{4}$, R. Kuschke ${ }^{5}$ \\ ${ }^{1}$ Climate Systems Analysis Group, University of Cape Town, Private Bag Rondebosch 7701, South Africa \\ ${ }^{2}$ School of Geography, Archaeology and Environmental Studies, University of Witwatersrand, Johannesburg 2050, \\ South Africa \\ ${ }^{3}$ School of Bioresources Engineering \& Environmental Hydrology, University of Natal, Pietermaritzburg 3209, South Africa \\ ${ }^{4}$ South African Weather Service, Private Bag X097 Pretoria 0001, South Africa \\ ${ }^{5}$ Institute for Soil, Climate and Water, Agricultural Research Council, Private Bag X79 Pretoria 0001, South Africa
}

\begin{abstract}
Reliable seasonal forecasting of climate, particularly for the rainy season for South Africa, has the potential to be of great benefit to users. Foreknowledge of temperature and rainfall conditions can assist planning, management and mitigation decisions for users from many sectors of the economy. Pre-requisites of a useful seasonal forecast, however, would include ease of interpretation, acceptable accuracy as well as efficient dissemination. This paper describes the process of the development, dissemination and use of seasonal climate forecasts in South Africa. We critically analyse the process and suggest proposals for further research and development. Also addressed are the needs of users, maximisation of potential forecast benefits and some proposals for more efficient distribution.
\end{abstract}

KEY WORDS: Seasonal forecasts $\cdot$ Forecast dissemination $\cdot$ Forecast applications

\section{INTRODUCTION}

In South Africa, seasonal forecasts generally consist of an outlook of precipitation and temperature for the rainfall season of a specific area. Such forecasts can be issued monthly throughout the year, or at least prior to the rainy season (September to March). In most cases the forecast is presented as a 3-mo average, and can entail monthly updates for each subsequent 3-mo period (South African Weather Services [SAWS]; www.weathersa.co.za/nwp/seasonal.html). Many such seasonal forecasts are produced for the Southern African region by a range of scientific, academic and meteorological institutions (SADC-DMC 2002). In South Africa, some are produced as the output of research projects as an ongoing forecast product development, while others are produced as formal products being disseminated by the institution respon- sible (e.g. SAWS, Universities, Research Councils, National Government Departments).

In regions that lack sufficient water resources to irrigate, and therefore depend on rainfall for farming, prior knowledge of the likely pattern of precipitation could lead to substantial improvements to food security as well as profits to commercial producers (Blench 1999, Hammer et al. 2001). South Africa is a relatively dry country with variable rainfall regimes. Accurate seasonal forecasts that could assist with the planning of planting, fertilisation and harvesting could help increase crop productivity and profitability as well as reducing agricultural losses (Hammer et al. 1996, Jury et al. 1999b, Jones et al. 2000). Most of the examples cited here are for crop production, but there are initiatives currently underway to improve the utility of forecasts for livestock production (e.g. Hudson \& Vogel 2003). 
One of the main purposes of this review is to explore the improvement of the application of forecasts to the benefits of users, and also to guide forecast producers towards the production of more useful forecasts. The role of key institutions in the forecast system is assessed with a view to characterising the 'end-to-end' nature of the process. Such a characterisation will allow forecasters and application researchers to identify gaps in the process and suitable points for intervention to improve this process, i.e. from the production of forecasts by scientists to the uptake and use of the forecasts by an end-user (e.g. industry, farmer or other).

We begin by describing the climatology underpinning seasonal forecasts including the role of ENSO and other factors that affect summer season rainfall in South Africa. This is followed by a review of the institutions currently engaged in seasonal forecast production, their dissemination and potential use. Finally we critique the usefulness and overall current use and uptake of seasonal forecasts in South Africa.

\section{THE PROCESS OF SEASONAL FORECAST PRODUCTION}

The current state-of-the-art in seasonal prediction worldwide is well reviewed by Goddard et al. (2001). The sophistication of the tools used varies according to institution, but invariably involves a dynamical modelling approach and/or a statistical approach. Both approaches rely upon input data, which could be observed or modelled sea-surface temperatures (SSTs), historical climatic data, satellite information, or a combination of these (Goddard et al. 2001).

The predictability of seasonal rainfall results primarily from the influence of SSTs, or so-called 'boundary conditions', on the atmospheric circulation (Palmer \& Anderson 1994, Washington \& Downing 1999, Goddard et al. 2001). Throughout most of the tropical oceans, including the equatorial Pacific Ocean where El Niño Southern Oscillation (ENSO) events occur, SST anomalies may persist for up to 6 mo or more (Goddard et al. 2001), making seasonal climate forecasting possible.

Foremost among seasonal prediction activities, because of its important global influence, is the ENSO phenomenon. The Southern Oscillation Index (SOI) drives the prediction of ENSO events, and the warming of the Pacific is the leading indicator. Most forecast models (dynamical and statistical) were able to predict the onset of the 1997/98 El Niño, albeit at lead times varying between 3 and $1 \mathrm{mo}$, and were not inaccurate in the case of USA (Barnston et al. 1999) or South America (Jones et al. 2000).
The relationship between Southern African rainfall and the El Niño phenomenon has been evident for some time. Ropelewski \& Halpert (1987, 1989, 1996) showed a positive correlation between the SOI and Southern African rainfall. In South Africa, the wet summer season corresponds to the mature phase of the ENSO, when the range of anomalies in ocean surface temperatures and in atmospheric parameters is the largest.

El Niño impacts are at a maximum in the southeast of the continent, in January-February-March (JFM) (Lindesay 1988, Lindesay \& Vogel 1990). El Niño occurrences (warm anomalies in the Eastern Pacific) are usually, but not always (Mason \& Mimmack 1992) associated with droughts in a large part of the subcontinent. There are few correlations between the rainfall index in Southern Africa and the several indices reflecting the state of the Pacific (Richard et al. 2000). In fact, the relationship between Southern African rainfall and El Niño/La Niña events seems to be temporally unstable. Seasonal climates may depend to a greater or lesser extent on SST variability in ocean basins other than the Pacific, suggesting that forecasts of SSTs in these other basins would be desirable (Mason et al. 1999). Indian Ocean SST anomalies, for example, correlate with Eastern and Southern African rainfall variations. (Goddard \& Graham 1999, Reason \& Mulenga 1999)

Rainfall records from previous years can, however, provide an indication of what can be expected during specific ENSO or (anti-ENSO) episodes. El Niño events differ in strength, and a range of rainfall outcomes can therefore be expected. This is where a specific SOI correlation has advantages. On the whole, for the period 1890 to 1989, El Niño events have led to mean negative

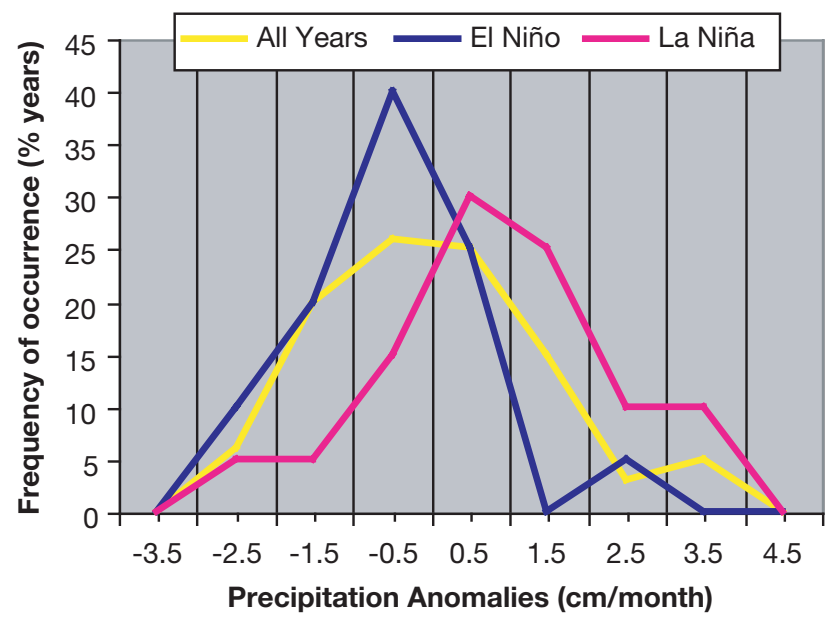

Fig. 1. Precipitation anomalies of ENSO - East Southern Africa, November to May 1890-1989 (source IRI, New York, using data from NCEP, Climate Prediction Center USA) 

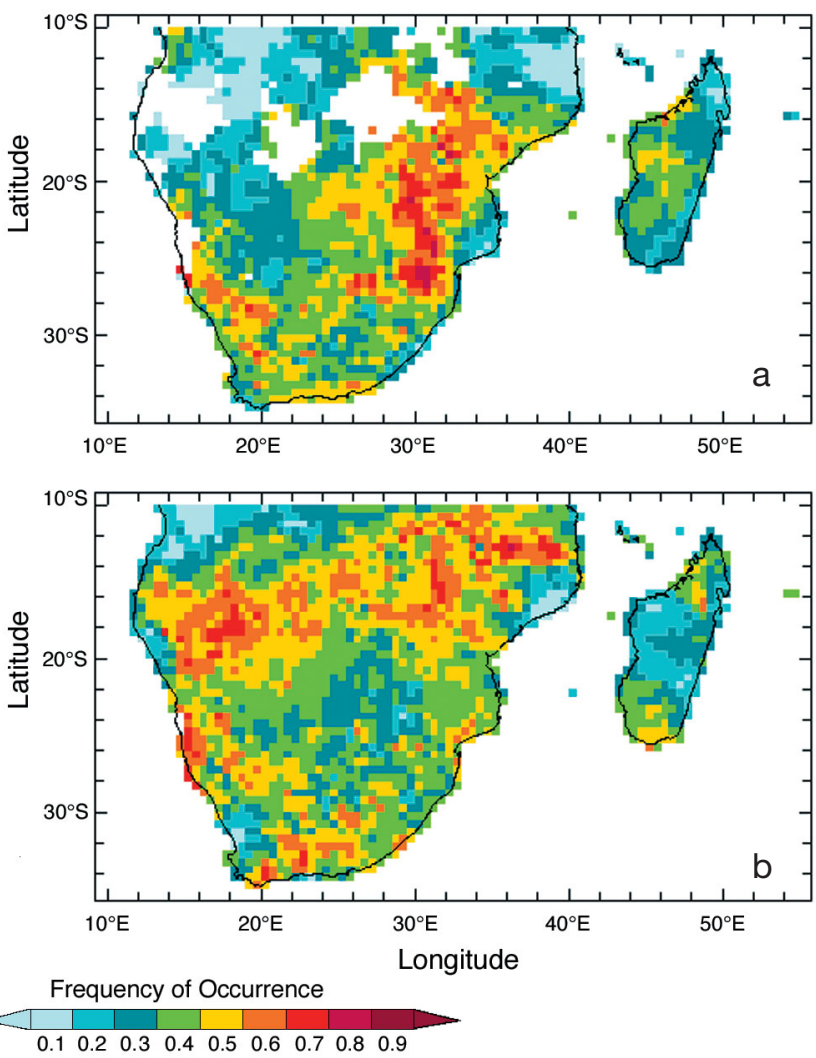

Fig. 2. Occurrence of below-normal seasonal (a) OND, and (b) JFM rainfall over Southern Africa during the 10 strongest recorded El Niño events (NINO 3.4 SST anomalies OND 1950-1995) (after Mason \& Goddard 2001, IRI website http:// iridl.ldeo.columbia.edu/SOURCES/.IRI/.Analyses/.ENSO-RP/ $.0 \mathrm{p} 5 \mathrm{deg} / . \mathrm{prob} /)$

rainfall anomalies (Fig. 1). In contrast, La Niña conditions show positive anomalies.

Fig. 2 shows enhanced probabilities of below-normal rainfall amounts over especially the northeastern interior of South Africa during El Niño events. The likelihood of dry conditions is greatly increased in the JFM part of the season, especially since the 1970s (Richard et al. 2000).

As stated above, El Niño events, although usually associated with below-normal rainfall over much of Southern Africa, are not the only factor influencing Southern Africa's seasonal rainfall. A warming of the Indian Ocean during El Niño events appears to be important in providing a linkage between Southern Africa and the equatorial Pacific Ocean through the weakening of tropical convection over this region (Lindesay 1988, Mason \& Goddard 2001). Local SST forcing is also evident from adjacent oceans, particularly the warm Agulhas Current, the strongest western boundary current in the southern hemisphere, and its inertial re-circulation over the SW Indian Ocean. Several regional studies have explored its influence on summer rainfall along the southeast coast of South Africa (Jury et al. 1993, Mason 1995) and over the subcontinent as a whole (Reason 2001).

Based on this premise, seasonal forecasting methodologies are developed such that they include the signal from these tropical oceans. The dynamical approach employs atmospheric general circulation models (GCMs) with prescribed SST fields or coupled ocean-atmosphere GCMs that attempt to simulate to fullcoupled ocean-atmosphere system and the feedback between the atmosphere and ocean. These models simulate the general circulation of the atmosphere and ocean using 4-dimensional prognostic equations and complex physics packages. The statistical approach, on the other hand, seeks a direct (often a timelag) relationship between SSTs and local climate. The relative performance of these 2 approaches differs from region to region, with each having its own specific advantages for different applications.

Notwithstanding the associations between SSTs and rainfall in Southern Africa (Mason 1995), the largest portion of the variability remains unexplained. Studies have shown that signals in the mid-latitude eddies also have a strong influence on the development of tropical-temperate-troughs, which are a major contributor to summer rainfall in Southern Africa (Todd \& Washington 1999). Furthermore, local feedbacks through vegetation and soil moisture are yet to be quantified for Southern Africa but certainly must play a role in local climate variability. The complexity of the interaction of these influences, particularly in the Southern Africa region where variability is high but predictability through strong teleconnections is low, poses a challenge to seasonal prediction. This highlights the importance of users and even producers of forecasts not to over-simplify the prediction process and its interpretation for this region, e.g. El Niño equals drought.

In this regard it is important to also recognise the relationship between forecast producers and forecast users. A forecast process that does not take into account the requirements of the end-user is not serving to advance its usefulness (Rosenzweig 2001). Furthermore, forecast production involves a degree of subjective and objective decision making. Scientists have inherent leanings towards particular types of forecast generation, which in their experience have proved more successful than others. The early successful identification of an approaching ENSO event is often regarded as more important than recognising the variation within a non-ENSO year.

The impact of ENSO events on South African rainfall patterns should not be overestimated but it is the magnitude of the impacts which is most important for the rainfall dependent forecast user. In most cases the skill 
or accuracy of a forecast in determining both the event itself as well as the magnitude is proportional to its usefulness.

As Blench states, there is also a problem with the indiscriminate use of forecasts:

The accuracy of forecasts depends on effective measurement of known predictors, model quality and local interpretation. In 1997-8, indicators showed that an El Niño was in progress, resulting in warm water off the coast of Chile, and drought in NE Brazil, southern Africa and Melanesia. Preparations were made throughout southern Africa, causing considerable scepticism when the expected drought failed to materialise. Similarly, predictions for January to March 1999, adjusted by the SARCOF meeting in December 1998, predicted above average rainfall in southern Africa, whereas observed rainfall was in fact lower than average. These technical failures have had the effect of enforcing more humility on climatologists and called into question the utility of widespread dissemination of forecast material.

(Blench 1999, p. 2)

\section{FORECAST PRODUCERS IN SOUTHERN AFRICA}

A range of institutions in the Southern African Developing Community (SADC) region produce different types of forecasts, including meteorological services and university research groups. The Southern African Regional Climate Outlook Forum (SARCOF) World Meteorological Organisation (WMO) mandated process combines these forecasts, and produces a regional outlook every year. These provide a regional context within which local forecasts are configured, produced and used. Forecast production is described here first for the region and then for South Africa.

SARCOF is the WMO-mandated regional seasonal weather outlook prediction and application process adopted by 14 member countries of the SADC.

\subsection{Regional institutional processes}

SARCOF facilitates information exchange as well as interaction among forecasters, decision-makers and climate information users in the region. Its main objective is to promote technical and scientific capacity building in producing, disseminating and applying climate forecast information in weather-sensitive sectors of the region's economies.

In previous years, the SARCOF process started with $6 \mathrm{wk}$ of pre-SARCOF capacity building training workshop, followed by the SARCOF meeting itself and then the SARCOF mid-season correction meeting.

The pre-SARCOF capacity building workshop is intended to enhance the technical ability of forecasters in seasonal weather forecasting. The training workshops enable participants to acquire skills in climate modelling, including interpretation and application of local knowledge and downscaling techniques. The main objectives of the workshops are:

- To enhance the capacity of the SADC National Meteorological Services in data processing, diagnosis, and seasonal climate prediction,

- To develop empirical/statistical prediction models for each country and to downscale general circulation models (GCMs) products to national level,

- To generate national seasonal climate forecasts for subsequent input into the SARCOF meeting,

- To promote application of climate information and prediction by various end-users for the socioeconomic development of the region.

Following the capacity building workshop, the SARCOF outlook meeting is held. Seasonal outlooks generated by a range of methods at national, regional and international levels are presented to participants in order to formulate a consensus forecast for the region. The forecast generation applied by SARCOF entails the use of coupled ocean-atmosphere models, physically based statistical models and expert judgement. Probability distributions are established to indicate the likelihood of below-, near-, or above-normal rainfall for the region.

The initial process involves the following steps taken by each country's National Meteorological Service (NMS) prior to the SARCOF preseason consensus meeting:

- Demarcating regions by homogeneous zones. Each country is divided into homogeneous rainfall zones. This is done with the use of statistical analysis technique applying principal component analysis (PCA). Stations with similar characteristics of rainfall variability are grouped together. Rainfall generating mechanisms may differ from one zone to another and seasonal rainfall totals are not by themselves a critical factor in this analysis method. Stations with different annual rainfall means may thus have the same variability characteristics and are thus grouped in the same zone. Knowledge of the climatology of the local area is of importance when applying this technique.

- Developing statistical/empirical seasonal rainfall forecast models. Statistical models are developed with the use of multiple regression analysis to derive empirical/statistical analogues.

- Validation of forecast models. Each forecast model is tested and cross-validated by the use of contingency tables and the skill of each model evaluated.

- Formulation of seasonal forecast. The seasonal forecast for the coming season is formulated for each zone indicating the likelihood of below-normal, normal or above-normal rainfall for the coming season. 
The consensus discussion involves the presentation of each country's forecast and the subsequent combination of rainfall probability regional borders. The Forum reviews the state of the global ocean-atmosphere system and its implications for this region. The principal factor taken into account is the current state of the SSTs over much of the tropical Indian and Atlantic Oceans.

Coupled global ocean-atmosphere models, physically based statistical models and expert interpretation are used in the development of the outlook. The current status of seasonal forecasting methodologies allows prediction of spatial and temporal averages, and may not fully resolve all factors that influence regional, national and local climate variability. In this process the regions are merged at the country borders to create a fluid and contiguous series of regions throughout the SADC area. Subsequent discussion revolves around the actual tercile probabilities. Ultimately, consensus is reached and a map is produced, which may vary somewhat from an individual country's forecast. The rainfall forecast from the SAWS for September to November 2002 is presented in Fig. 3 and that from the September 2002 SARCOF-6 meeting in Fig. 4.

The mid-season correction is an important follow-on from the pre-season meeting. At this meeting the season thus far is assessed and the latest model outputs consulted. The forecast produced can vary substantially from the pre-season issue. As many as 6 updates can be issued, as was the case in 2001/02.

Fig. 5 shows the (a) pre-season and (b) mid-season forecast for the same period (JFM) in 2002.

The dissemination of the SARCOF forecast's information and products to the users is accorded high priority in the SARCOF process. In order for the outlook to reach all layers of the community, various media organs such as radio, television, newspapers, and press releases are used. The target groups are policy-makers, disaster management authorities, drought relief agencies, institutions responsible for food security, as well as other weather and climate sensitive sectors, including the general public. Some SADC member NMSs may choose to disseminate their own forecast, while providing access to the SARCOF seasonal outlook (and updates).

In South Africa, the SARCOF forecast dissemination appears to be limited to the SAWS website (www. weathersa.co.za/nwp/seasonal.html). It is generally reasoned that the SAWS resources and forecasts, having served as input for SARCOF, are adequately reflected in the SAWS long-term forecast itself. It can be seen from Figs. $3 \& 4$ that the SARCOF consensus forecast differs slightly from the SAWS forecast for that particular forecast period. (a)

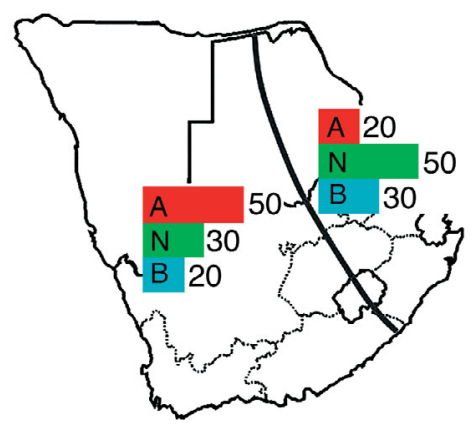

(b)

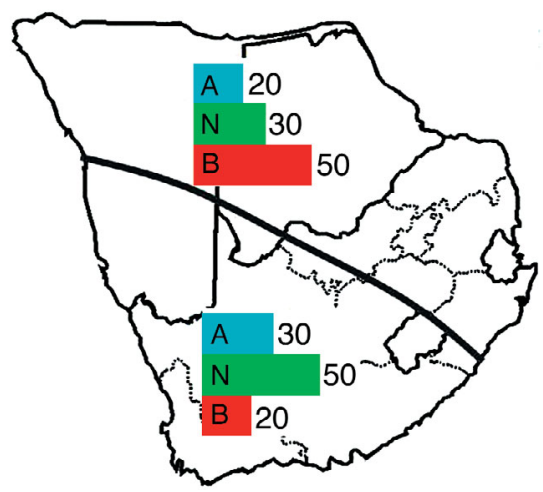

Fig. 3. SAWS seasonal forecast. Expected mean (a) temperature and (b) rainfall, for September to November 2002. (Source: SAWS). A: above normal; N: near normal; B: below normal

\subsection{South African Weather Service (SAWS)}

We now turn to examining the national forecast process, end-users and those tailoring forecasts for their own particular uses, taking the examples of the maize and sugar industries.

The SAWS is the country's national meteorological service, with a permanent representative at the WMO. In terms of its WMO obligation, it is the primary weather and climate information service provider in South Africa. As one of the services it offers, the SAWS began the Long-term Operational Group Information Centre (LOGIC) in 1997. This centre was amalgamated with the SAWS Central Forecast Office in 2003 under the division 'Long-term forecasting' in an effort to begin a seamless forecast product range. The new National Forecast Centre (NFC) is responsible for providing guidance and warning of national weather to regional forecasting centres and the media.

The scientists working on long-term forecasting projects have been tasked to produce and disseminate a monthly 3-mo forecast through the NFC. A multitiered forecast system consisting of a dynamic modelling process, combined with a statistical approach and consensus discussion is employed to produce the seasonal forecast (Landman et al. 2001). The input to the 


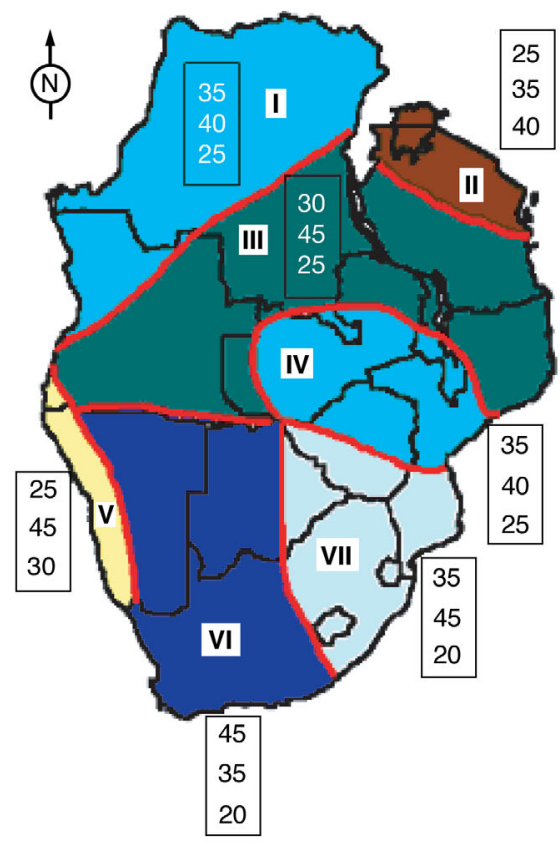

consensus discussion is derived from both in-house and outside sources.

The in-house, multi-tiered system begins with a prediction of near-global SSTs using canonical correlation analysis (CCA). This technique has been shown to be successful in predicting SST anomalies up to several seasons in advance (Barnett \& Preisendorfer 1987). Any identified warming or cooling of global-scale SSTs is used as a predictor in the local CCA model to predict monthly SST anomalies of the equatorial Pacific and Indian Ocean basins over the 10-yr retro-active period from 1987/88 to 1996/97 (Landman \& Mason 2001). Even though SST predictions for non-ENSO years are satisfactory, most of the predictability of equatorial SSTs is associated with ENSO. The magnitude of strong events is frequently underestimated in CCA predictions, which may negatively impact the response of a GCM to such strong SST anomalies. For this reason a variance adjustment is done on the predicted anomalies.

In the second tier, the Centre for Ocean Land Atmosphere (COLA) T30 GCM is integrated forward 8 mo from 10 sets of initial conditions (each time-lagged by $12 \mathrm{~h}$ ) to create a 10-member ensemble. The initial conditions are derived from the operational global atmospheric analyses received from the National Centers for Environmental Prediction (NCEP). A parallel ensemble suite is generated using the same initial conditions but using persisted SST anomalies calculated from the latest observed SST data. Three-month running forecasts of rainfall and SST anomalies are then calculated for each ensemble mean and used as part of the suite of

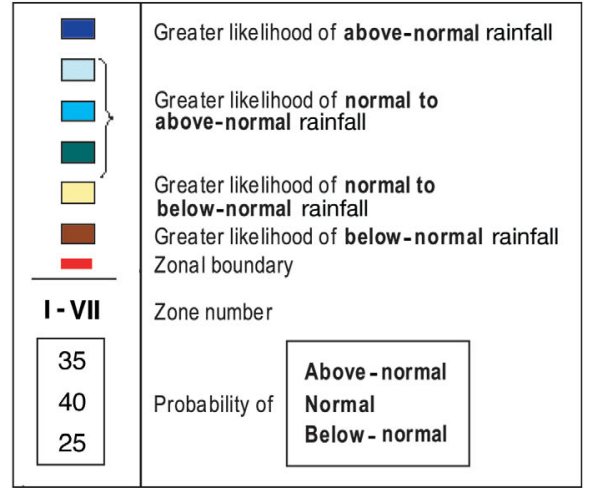

Fig. 4. SARCOF consensus forecast September 2002. (Source: DMC, Harare). Zone I: likelihood of normal to above-normal rainfall; Zone II: likelihood of normal to above-normal rainfall; Zone III: likelihood of normal to below-normal rainfall; Zone IV: likelihood of normal to above-normal rainfall; Zone V: normal to above-normal rainfall; Zone VI: normal to abovenormal rainfall; Zone VII: climatology

products in a monthly consensus discussion. These anomalies are calculated using a model climate that was derived from a 5-member ensemble 14-yr simulation from 1986-1999 (Tennant 2003).

In parallel with this second tier, statistical forecasts of precipitation and temperature are made using CCA (Landman \& Mason 1999). These are calculated through time-lag relationships between South African regional rainfall and global SSTs. These statistical models are trained and validated by historical data enabling forecast skill estimates to accompany the forecast. These forecasts are used as input in the final tier.

The third tier utilises statistical methods where large-scale circulation fields generated by the GCM are downscaled (Von Storch \& Navarra 1995, Landman et al. 2001) to specific rainfall regions. Bias-corrected GCM output from tier 2 (Tennant 1999) is input to the CCA regression equations, which are used to perform the downscaling process in a 'perfect prognosis' approach. The CCA regression equations are trained using observed circulation and regional rainfall to produce a regional rainfall prediction. This method demonstrated skill in several regions of South Africa (Landman et al. 2001). A model output statistics approach has also been successful for monthly forecasts in South Africa using the same GCM (Landman \& Tennant 2000). Plans are currently underway to improve the downscaling endeavours at SAWS by making better use of ensemble spread information and also to provide more information on intra-seasonal variability. 

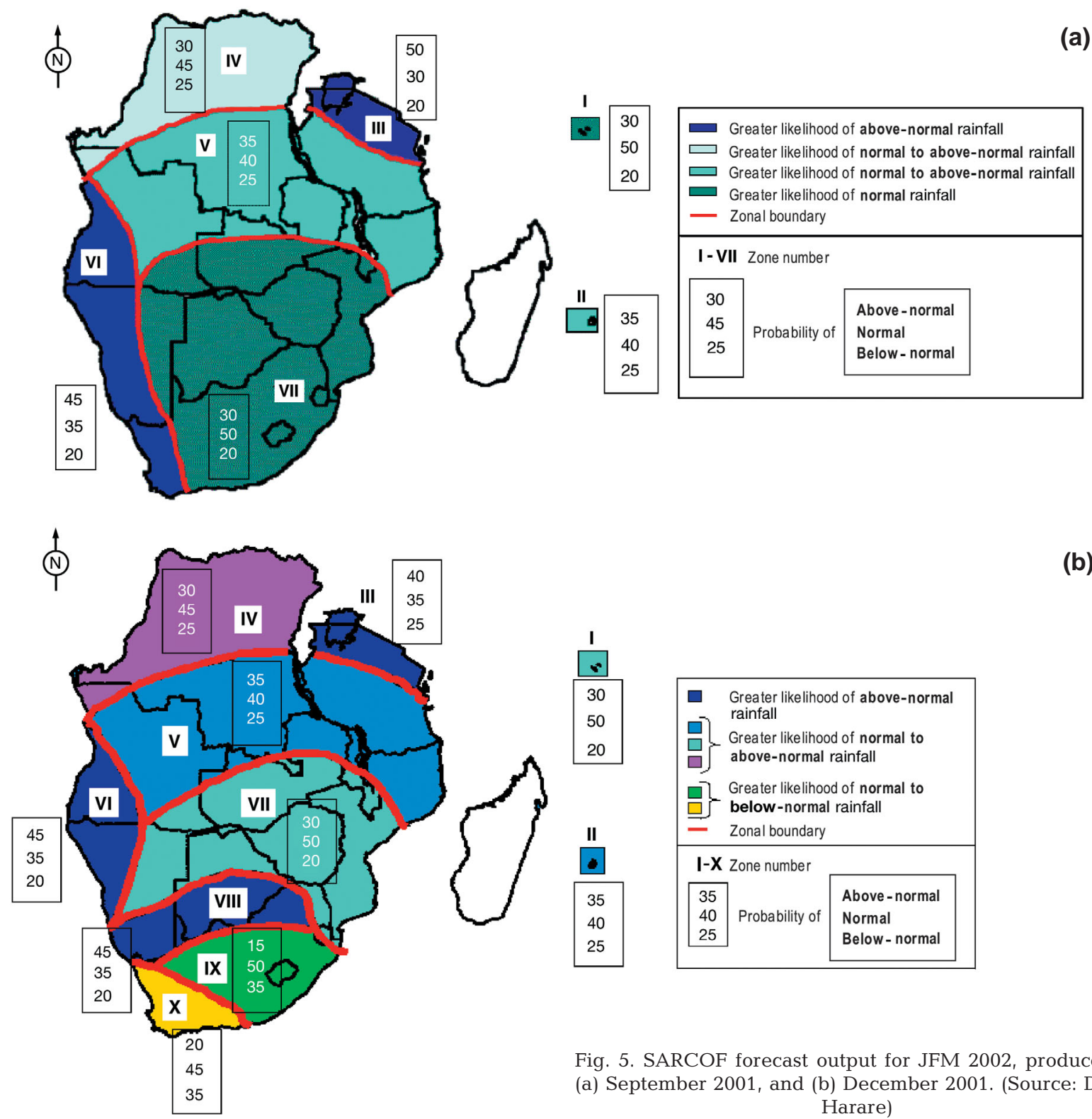

The final tier comprises a monthly discussion between the long-term forecasters at the SAWS. Input from the COLA and CCA dynamical and statistical analyses, as well as model output supplied by IRI (International Research Institute) and ECMWF (European Centre for Medium Term Weather Forecasts) are analysed and a probability forecast is generated (Table 1).

The dissemination of the SAWS seasonal forecast is available via the SAWS website (Fig. 3), selected email and fax recipients (including government departments, commercial agriculture and banks) and an automated cellphone number managed by the Central Forecast Office. Some interpretive guidelines are given with the forecast explaining, inter alia, the meaning of probability and the tercile system. (b)

(a)
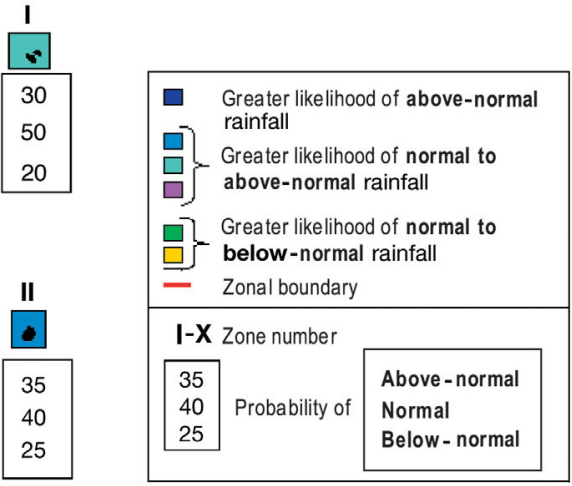

Fig. 5. SARCOF forecast output for JFM 2002, produced in (a) September 2001, and (b) December 2001. (Source: DMC, Harare)

Table 1. Forecast generation process adopted at SAWS

Discussion process at SAWS

- Grouping: There is a physical grouping of similar forecasts

- Weighting: Using previous experience as a guideline, forecasts that have had historical success are favoured

- Discarding: Outlier forecasts are discarded after due consideration

- Compilation: Regionalisation of the forecasts is performed and dividing lines (of which a maximum of 3 are used) are created. This is followed by the terciles probabilities being averaged and allocated to the created regions 


\section{Specific caveats are issued with the forecast:}

The potential of climate prediction arises NOT from timing and location of individual weather events, but for averages over months and seasons. Climate forecasts are distinctly different from weather forecasts, because they cover relatively large regions over a long period of time. The weather at particular locations and at specific times may sometimes appear to contradict the climate forecast.

and,

Seasonal forecasts are NOT suitable for small, localized areas for specific days.

(SAWS website: www.weathersa.co.za/nwp/seasonal.html)

Recently (August 2003) a new Global Forecasting Centre for Southern Africa (GFCSA) website was conceived and launched by 3 participating institutions: SAWS, the Climate Systems Analysis Group (CSAG) at University of Cape Town, and Laboratory for Research and Training in Atmospheric Modelling at the University of Pretoria.

The prime function of the GFCSA is to operate and maintain an operational long-range forecasting (LRF, from $30 \mathrm{~d}$ up to $2 \mathrm{yr}$ ) system for the globe from where Regional Climate Centres and National Meteorological and Hydrological Services within SADC, as well as the international research community involved in the development of long-range forecasts, can obtain relevant global LRF products. The products from the different institutions are displayed and explained online at www.gfcsa.net.

\subsection{Other institutional inputs to the forecast system in South Africa}

\subsubsection{University of Cape Town HadAM3 Model}

At the University of Cape Town, seasonal and monthly forecasts are made using the United Kingdom Meteorological Office Atmospheric General Circulation Model (AGCM) HadAM3. The mixed phase precipitation scheme is included in the model integrations as this improves the model precipitation over Southern Africa. A 10-member ensemble of the HadAM3 AGCM has been integrated forward with observed (Reynolds) SSTs. This ensures that aspects of the model (e.g. soil moisture and temperature) are in equilibrium with the model precipitation as forced by historical SSTs.

Forecasts are produced for 6 mo into the future using forecast SSTs, which are constructed by adding the COCA (CSIRO Australia) model's SST forecast anomalies to the Reynolds SST climatology, except where persisted observed SST anomalies are used for the first month.

The 3-mo average forecasts are expressed as anomalies of the ensemble mean minus the mean of a 15-yr climatology produced using observed SSTs (1982-2000) (see Tennant 2003 for a comparative verification of this climatology with that of the COLA GCM used at SAWS). For precipitation, the result is divided by the mean of the climatology ensemble and expressed as a percentage of normal (Fig. 6). The contour lines indicate where the mean of the ensemble forecast was different to the mean of the model climatology at the $90 \%$ significance level according to a Student's $t$-test.

The forecast is still in its experimental phase and is thus not disseminated further than on www.gfcsa.net and as a resource for SAWS and other forecasting institutions.

\subsubsection{Other}

Other seasonal forecasts are produced by a variety of individuals or institutions. The methodologies vary from statistical and numerical analysis to dynamical modelling.

At the University of Zululand, the Climate Impact Predictions group has been producing long-range climate outlooks for Southern Africa since 1991. These forecasts utilise ECMWF products combined with SSTs and air pressure measurements from the Pacific, South West Indian and South Atlantic Oceans. In 1999, on the basis of strong La Niña conditions, a prediction of above-normal rainfall for NE South Africa and Mozambique was produced which proved correct when severe flooding afflicted Southern Mozambique.

Teleconnection studies (e.g. Jury et al. 1999a) have also been used to assemble a wide selection of predictors to develop statistical multivariate models for forecasting climate-related impacts over Southern Africa. Application of numerical model forecasts at grid cell scale achieves a hit rate around $50 \%$ that is below costbenefit to users (Landman et al. 2001). Hence model forecasts are most reliable at a spatial scale near $106 \mathrm{~km}$ and a long range time scale (M. R. Jury et al. unpubl.).

\section{4. 'Intermediary' institutions and agencies active in forecast application}

\subsubsection{National Department of Agriculture, Agricultural Research Council}

Application of seasonal forecasts in South Africa is being undertaken by a number of institutions and potential end-users. The Agricultural Research Council's Institute for Soil, Climate and Water (ARC-ISCW), for example, utilises the seasonal forecasts to develop 


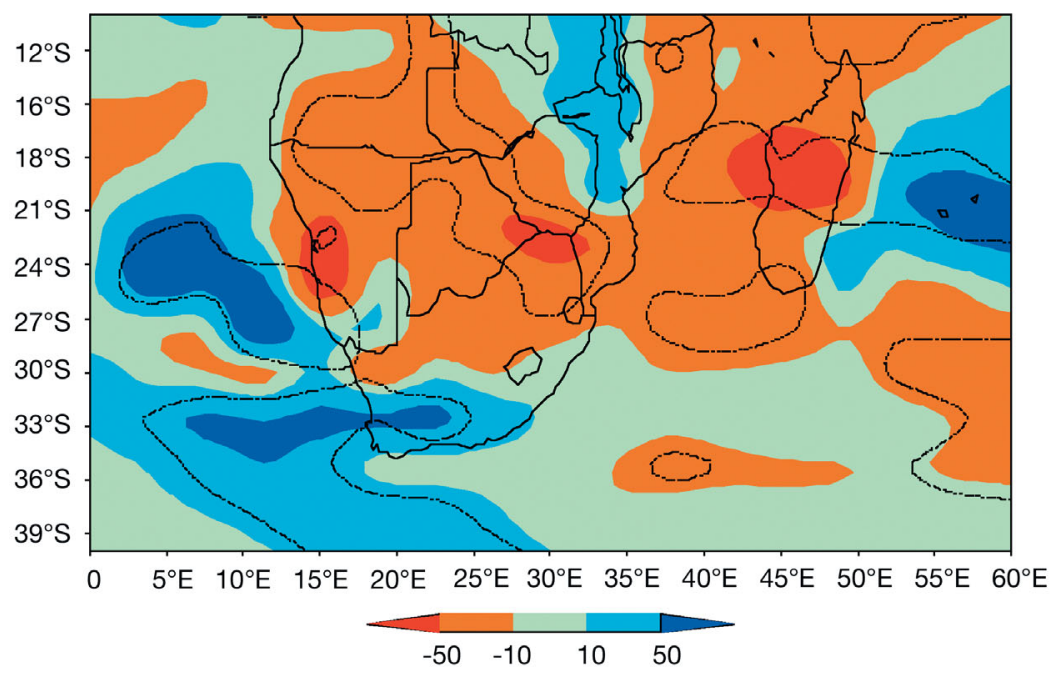

Fig. 6. Rainfall forecast for 2003 ASO (August, September, October) precipitation (\% of normal), using HadAM3 MPP issued on July 14, 2003

\subsubsection{Maize Vision}

Maize Vision is a monthly electronic product issued on a commercial basis by Enviro Vision in conjunction with the ARC-ISCW. The aim is to provide users (mostly commercial maize farmers) with a monthly analysis of the received and anticipated monthly rainfall, as well as the significance for specific activities in the maize-growing region.

It is based on the latest observed SSTs from the Drought Research Unit (Queensland, Australia) and reported SOI (Australian Bureau of Meteorology), and uses a rainfall and crop model, respectively, to predict rainfall and crop yields for specific districts based on their rainfall records. Sea surface predictions are analysed and

and publish regular advisories for farmers (South African National Department of Agriculture 2003, Agricultural advisory; available at www.agis.agric.za). The National Agrometeorological Committee (NAC), under the chairmanship of the National Department of Agriculture, Directorate for Agricultural Risk Management, convenes regularly during the rainy season to assess the outlook provided by the SAWS. The previous month's actual rainfall figures are compared to the forecast, as well as the long-term median, and they are then interpreted in terms of the agricultural prospects for the following month. For example, in February 2003, it was observed that the rainfall onset was late, but that the rain for December, January and February was well distributed spatially and temporally. The interpretation that followed predicted that late plantings would do well.

In an experimental model, based on the crop-climate-soil interaction, the seasonal forecast provides the initial input, while a GIS system produces cropspecific production levels. The eventual aim is to incorporate the SAWS outlook into this model, which would then relate the seasonal outlook to yield values which are spatially variable due to the varying interaction between climate, plant and soil factors. Other indices like heat stress (temperature driven) etc. could be investigated as the model develops.

Additional resources such as Normalized Difference Vegetation Index (NDVI) images and feedback from users help to develop the agricultural advisory into a useful working document. For farmers, this adds significant value to the seasonal forecast. The advisories are distributed through the existing network of extension officers and have been welcomed. their correlation with the ENSO phases and the subsequent effect on rainfall and temperature are discussed. From time to time crop scenario estimates are published for each province and the possible influence on prices discussed. The domestic and USA market price trends are shown in conjunction with the rand/dollar exchange rate.

Maize Vision is intended to give farmers (and other sectors) useful information from which pertinent decisions can be made. The decisions that could be influenced (as far as farmers are concerned) would include the selection of crop types, seed cultivars, fertiliser application, and even, as shown in the 2002/03 season, whether or not to invest in market futures, whereby a selling price is fixed ahead of time. Some limited advice is given to the recipients as far as climatic and crop conditions are concerned.

Currently there are over 600 subscribers to this service. The following excerpt and rainfall probability map (Fig. 7) are taken from Maize Vision No. 46, issued in June 2003:

The RSA maize crop for $2002 / 2003$ is estimated at about 8.6 to 9 million tons but controversy over areas still continues. Dry conditions hamper the planting of winter wheat and it is possible that the unplanted areas will go to early sunflower plantings for 2003/2004. Farmers are in a dilemma with large grain stock levels and low prices for most grain commodities in the country. The problem can grow in magnitude when farmers must take final decisions for next summer season. What is the best commodity to utilise water, especially when water is a restriction? From a pure production perspective maize is still the best alternative with the highest yields possible with enough available water. Taking commodity prices into account, the best alternatives at relative low water levels (but above a critical level) are winter wheat and sorghum. Demand for 


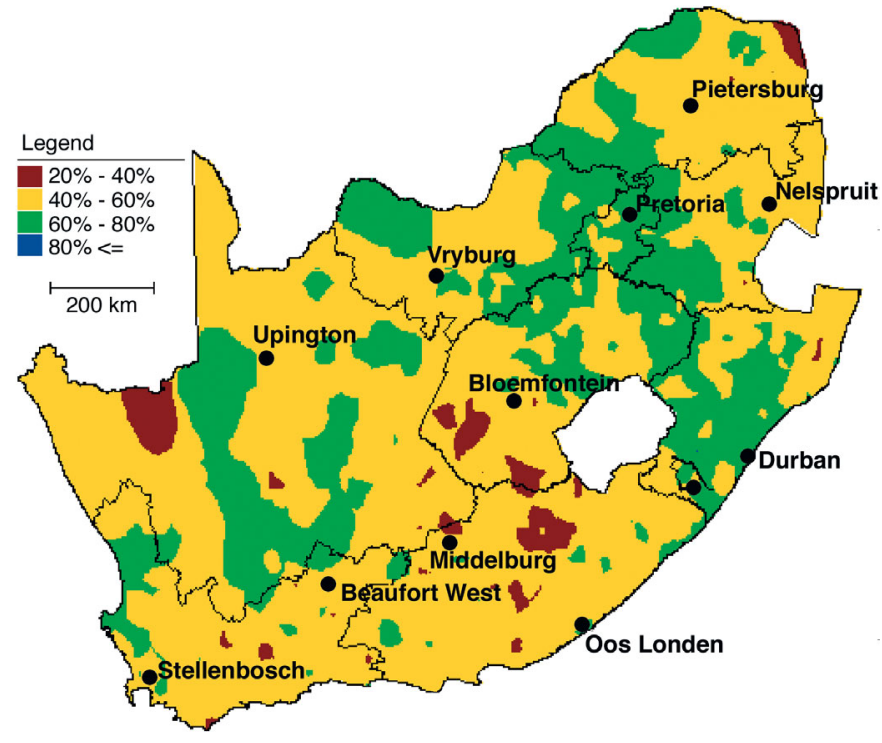

Fig. 7. Probability (\%) of exceeding median (normal) rainfall for October 2003 (Source: Maize Vision No. 46, Bloemfontein)

sorghum is small, winter wheat need special soil water conditions and cultivation and both are therefore not real viable alternatives. Groundnuts are a good alternative crop if available water is more than $450 \mathrm{~mm}$ during the season and sunflower when water is very restricted.

It seems that the price of especially maize will stay under pressure due to high grain stock levels, favourable USA conditions, strong rand currency, marketing pressure when farmers are going to need money to finance input costs and expected more favourable rainfall conditions for next summer.

Some conclusions:

- Where possible it is currently probably better to plant winter wheat than sunflower in early summer

- Groundnuts are a very attractive alternative if more than $400 \mathrm{~mm}$ water is available

- Sorghum is currently a very good alternative provided that a market is established before planting of the crop

- Sunflowers are a good alternative only at very low water levels (and poor soil)

- Groundnuts are not a viable alternative with available water levels lower than $350 \mathrm{~mm}$

- Taking markets, labour and special production conditions for other crops into account, maize seems to be the only 'alternative' for mass production.

(Maize Vision No. 46, June 2003)

\subsubsection{South African sugar industry}

Climate forecasts in the South African sugar industry are used primarily with the emphasis on providing operational crop estimates (McGlinchey 1999, Everingham et al. 2002). Singels \& Bezuidenhout (1999) have demonstrated links between El Niño, rainfall and crop yields in the South African sugar belt. Mc-
Glinchey (1999) and Bezuidenhout \& Singels (2001) based their crop estimates systems on the SAWS 3-mo forecasts as well as the Climate Impacts Prediction Centre (CIP) based at the University of Zululand. Jury (1998) also provided sugarcane production estimates using statistical relationships with various climatedriving forces, such as the SOI and Southern Ocean air pressure.

Bezuidenhout \& Singels (2001) used the CANESIM (Singels \& Donaldson 2000) crop model to add value to the climate forecast. This model simulates daily crop response to agroclimatic conditions. The model is used to simulate the crop up to the last date containing actual observed weather data. Thereafter, an analogue system (Everingham et al. 2002) is used to complete the season. The analogue system entails the identification of historic years that are likely to become a suitable substitute for the remainder of the season. Historic years are ranked according to their total rainfall (overlapping with the forecast lead time). Thereafter, a number of below-normal, normal and above-normal historic analogues corresponding to the SAWS percentages associated with the below-normal, normal and above-normal terciles are selected. This approach causes the crop model to complete the current season along a number of different paths. The spread of anticipated final yields, as achieved under the different analogues, enables the forecasters to express the uncertainty of the crop estimate. Decision-makers have identified forecast uncertainty as a vital component of crop estimates (Bezuidenhout 2001). The above-mentioned estimates were done for different climate stations and final results were aggregated to larger areas (Bezuidenhout \& Singels 2001).

Crop estimates are distributed (mainly by email) to estate managers, mill operators, milling company representatives, grower representatives and national management structures (McGlinchey 1999, Bezuidenhout \& Singels 2001). Estimates for the South African sugar industry have been disseminated since 2000, normally starting in February prior to the opening of the milling season and updating estimates every second month thereafter.

The information is valuable to a wide range of decision-makers functioning at different stakeholder levels within these industries. At the farm level, growers could, for example, reduce their fertiliser applications and intensify some of their pest and disease controls if below average yields are expected. At the mill level, decision-makers may use the information to estimate mill open and closure dates and allocate delivery slots to haulers and growers. Lumsden (2000) observed large potential economic gains at the mill level associated with accurate and well adopted crop estimates. On a national level, stakeholders (such as the South 
African Sugar Association) may use the information to improve industry competitiveness through strategic financial and marketing planning (Everingham et al. 2002).

There is still scope for future improvements to these systems. Bezuidenhout (2001) and Everingham et al. (2002) highlighted the incorporation of climate forecasts with longer lead times, web based information dissemination, more frequent updates and estimates starting in September prior to the following year's milling season as areas of likely future research.

\section{FORECAST ACCURACY AND USEFULNESS ANALYSIS}

For forecasts to be useful a number of factors are required. These include an indication of their reliability, the skill-level of the forecast and the degree of uncertainty of the forecast. The accuracy of a forecast can be regarded as the level of agreement between the forecast and corresponding observations. The difference between these two is the error of the forecast. The verification of forecasts is part and parcel of their development. No single measure can reflect the 'accuracy' of a forecast and they are usually assessed according to a combination of the following:

1. Skill-the accuracy of a forecast relative to the accuracy of forecasts produced by some standard procedure. Climatology, persistence and chance (guessing) are considered to have zero skill

2. Reliability - is the average agreement or disagreement between the stated forecast value and the observed value 3. Resolution - the ability of the forecast to distinguish between predictions on a spatial and temporal scale. A high resolution forecast would be able to accurately distinguish between an area with a $50 \%$ chance of rainfall and an area with a $80 \%$ chance

4. Sharpness - this is the attribute of a forecast to tend towards a categorical prediction of 0 or $100 \%$. It is important when predicting 'all or nothing' events like tornados, hurricanes and hailstorms. Neither the skill, nor the resolution of the forecast is reflected by its tendency towards sharpness

5. Uncertainty - this relates to the 'difficulty' of the forecast situation. Elements of uncertainty in a forecast make it very difficult to predict elements at all, let alone with a degree of skill or with high resolution.

(after Stanski et al. 1989)

Thus, a forecast's skill would generally be measured by how many times in the past it has been correct, compared to some reference data, such as a climatology (Mason 2000). This would relate to the methodology used to produce the forecast and would make the methodology suitable for specific areas and unsuitable for others.

Despite improvements in production technique, methodology and technology, some uncertainty will always remain in climate forecasting. The forecasts should thus be regarded as shifts in probability distributions within a locality's climate.

Probability is used in forecasts based on specific conditions for which a forecast may have skill and expresses this in terms of uncertainty for specific areas for a specific time period. Such probability forecasts can never be completely wrong because they assume inherent uncertainty. Forecasts that turn out to be inaccurate are invariably misinterpreted to be wrong, when the observed outcome was simply less likely. It is however still valid to criticise a high probability forecast when it is inaccurate, as uncertainty that must have existed in the forecast, whether in the model or the forecaster's mind, should have been made explicit to users.

Forecasters have a responsibility to reveal the anticipated skill level as well as the uncertainty that exists within a forecast so that users can be sufficiently aware of the risks associated with acting on the specific information.

El Niño forecasts are especially susceptible to a high degree of variation that leads to difficulty in predicting climate conditions for the same degree of index strength. For example, the 1982/83 and 1997/98 events were both very strong as measured by changes in the Pacific, yet their impacts in Australia were completely different. Eastern and Southern Australia experienced a severe drought in 1982/83, resulting in damages amounting to AU\$8 billion (Cane 2000), but during 1997 average to above-average falls were common in May, and a dry spell over winter was broken by widespread and heavy rains in September with crop yields showing little if any negative effects (www.bom.gov. au/climate/enso/\#impacts).

The best example of this variation in Southern Africa occurred during the same episode. In 1997/98, indicators showed that El Niño conditions that previously had led to drought would affect many areas including Southern Africa. The SOI value for September 1982, prior to the 1982/83 El Niño, was -2.0, while in September 1997 it was -1.6. The media issued widespread warnings and preparations were made, but the expected severe drought did not materialise. One reason was that there was a surplus of available surface water and the soil moisture content carried over from the previous season was still high. The existence of the El Niño was an undeniable reality, but the impact on Southern African climate was not well understood (Dilley 2003).

In 1998, forecasts predicted above-average rainfall for the Southern African region in early 1999, based on La Niña observations, but the observed rainfall was substantially below average (Blench 1999). This was subsequently explained by the presence of a stationary 
area of tropical convergence that developed in the Mozambique Channel, causing subsidence and hence dry conditions (Klopper \& Bartman 2002)

It is intuitively possible that forecasts, especially when trained by specific signals, are more likely to be able to predict conditions outside the 'normal' range. It would seem to be more difficult to predict the conditions when there is no specific evidence of a 'dry' or 'wet' season. The range of normal conditions is most often one tercile or $33 \frac{1}{3} \%$ about the climatological mean.

Whereas this gives hope that extreme seasonal conditions will be accurately predicted, the large variation during 'normal' years can be exacerbated by poor forecasts especially if a dry period persists for a number of years. This would be a very typical situation for parts of Southern Africa. An agricultural drought (insufficient soil moisture to sustain crop growth), may be in existence before a meteorological drought (implying a current lack of rainfall) is recognised. Thus the prospect of agricultural drought may be overlooked by a forecast that predicts normal rainfall for a season following a dry one. For this reason forecasts need to be interpreted in terms of local conditions.

Increased forecast accuracy and resolution would improve forecast utility for users. The constraints listed above suggest that this may not be the case in the near future, however. Temporal and spatial scales of current forecasts are such that high-resolution forecasts are not practically possible. By increasing the resolution it seems that quality must be sacrificed. The specific nature of a forecast may enable it to predict some aspects of the future precipitation or temperature with more accuracy and these would be most useful. With this in mind it is important to focus on the specific needs of the users and to focus research efforts towards increasing skill and utility in these areas.

It has been shown (Cane 2000, P. A. Johnston unpubl.) that when seasonal forecasts are interpreted as being deterministic for specific locations and used as a guide by sectors such as farmers, they seem to be inconsistent and, in many cases, misleading. This happens firstly because the forecasts are probabilistic in nature, and, secondly, are often not intended for direct use at a local scale for specific applications (Plant 2000), but are disseminated as seasonal guidelines only (Nicholls 2000). An example of this arises when a high probability for above-normal rainfall for a 3-mo period is predicted. If a drier first month follows such a prediction in a specific region, can a farmer, who to a large extent relies upon a total amount of rainfall, expect that the following month would be all the wetter in his region to counter the dry period?

Not only does this lead to confusion among farmers, but also frustration among forecasters, who feel their predictions are being misinterpreted (Farago et al. 1993). This emphasises the need for tailored forecasts that will meet specific user requirements, in terms of actionable and mitigating responses. It also highlights the need for forecasters to be aware that their products may be presented as having more meaning (and thus influence) than was initially intended.

\section{FORECAST APPLICATIONS}

Part of the end-to-end chain of forecast production and use requires focusing attention not only on the 'science' of the forecast in its production phase but also on the dissemination and use of the product. How can we better understand the 'context' in which forecasts are framed, embedded and used? What cultural, socioeconomic and political processes currently possibly frustrate the use and uptake of forecasts? Do we 'know' and 'understand' the environment in which potential clients and users of forecasts operate?

Despite being able to intuitively forecast some changes in the climate, most societies have organised themselves to accept a range of climatic conditions that may occasionally produce surprises or extremes. Some groups and sectors have developed skills to predict the surprises, while others have developed a range of mechanisms which help to cope with the changes. Still others have learnt to accept the surprises as being part of life (Stern \& Easterling 1999). With the advent of scientific forecasting, the ability to be forewarned about 'surprise' climatic conditions may lead to substantial benefits to certain users. On the other hand, forewarning without the capability of 'forearming' could be regarded as counter-productive.

At present in Southern Africa and as shown above, a fairly narrow group of potential users actually receive forecasts, and a smaller group actually makes use of them. Agriculture, being heavily dependent on rainfall, comprises the main group of users. Efforts have been made in recent years to strengthen forecast utility to agriculture by targeting provincial and local scales of activity through sensitisation workshops as well as extension officer training in interpretation of seasonal climate forecasts. Users in commercial agriculture have traditionally had greater access to seasonal climate forecasts than users in developing agriculture, as they can potentially approach forecast producers directly (within South Africa, and internationally) through a variety of available channels, including television, the internet and private consultants (Walker et al. 2001). They also possess the greatest ability and resources to effect adaptation to climate stress. The above-mentioned outreach effort for extension officers is partly an attempt to correct this imbal- 
ance and bring the potential benefits of forecasts to developing agriculture (I. B. Kgakatsi pers. comm.).

A far wider range of users within agriculture, and within other 'climate-sensitive' sectors could, however, benefit from access to seasonal or monthly climate forecasts (were certain recommendations, including those described here, incorporated). Within agriculture, there is significant scope to improve existing uptake and use of forecasts by commercial agriculture, and to improve outreach to developing agriculture. Further work by key intermediaries described above such as the National Department of Agriculture, the Division for Agrometeorology and Climatology at ARC-ISCW and university researchers on developing the agricultural advisory and the role of the National Agrometeorology Committee (NAC) has great potential. The recognition by SAWS that local institutions in areas traditionally not well served by forecast outreach can be helped to develop roles as nodes of climate information reception, interpretation and dissemination is also very encouraging (Klopper \& Bartman 2002, Archer 2003). Finally, work at the SADC regional level explicitly recognises that forecasts tailored for agricultural commodities need research and development-South Africa has excellent ongoing tailored forecast activities, and this remains a further area of priority work (www.sadcfanr.org.zw, SADC Regional Remote Sensing Unit, Harare).

Great potential exists for access to and use of forecasts by key sectors such as health (e.g. seasonal climate forecasts are being incorporated into a Malaria Early Warning System in Botswana; WHO 2001), water (e.g. evolving work in South Africa looks at streamflow forecasting and the use of seasonal forecasts for reservoir management), disaster mitigation (e.g. the use of seasonal climate forecasts for long-term contingency planning for floods and droughts at the national and provincial level), forestry (e.g. planning for increased seasonal probability of fires), fisheries (e.g. the impact of ENSO events on fish recruitment on the west coast of Southern Africa) and natural resource management (e.g. use of seasonal climate forecasts in management of conserved areas). 'Sectors' here refer not just to formal government departments, but also include other actors within civil society, such as non-govermental organisations involved in public health initiatives.

Forecasts may be available with a range of accuracy and levels of reliability - but are they of any use to a particular user, how can their value be estimated, and how can they best be used? Various tools are available to help address such issues in seasonal forecasting. Examining the Receiver Operating Characteristic (ROC) curve (Mason 1982) can facilitate optimal use of forecasts, and economic value can be estimated with simple tools such as the Cost/Loss Model (Murphy 1997). Although analyses such as these are a good starting point, in practice the detailed applications will have to be defined interactively with individual users or user communities.

At SAWS application-oriented research (Klopper \& Bartman 1999, 2002) has investigated user interfaces and dissemination methods. Commercial farmers were polled and the effectiveness and improvement possibilities of forecasts were assessed. A number of other researchers have investigated the uptake of seasonal forecasts in the Southern African region (Vogel 2000, Walker et al. 2001, Archer 2003, Vogel \& O'Brien 2003, Ziervogel \& Calder 2003, Ziervogel 2004, P. A. Johnston unpubl.). Such work has not only focused on the match between the 'science' of forecast production but has also examined the wider societal context in which forecasts are embedded (e.g. local knowledge systems, the role of traditional knowledge), what causes problems to uptake (e.g. access to information, access to credit) and how these constraints can be overcome. Some of this exploratory work has begun but much more effort needs to be given to this important area of research.

As described above, the NDA (ARM), ARC and SAWS have embarked on a project of early warning awareness to agriculture and have trained 122 officers so far. They have expressed the need to extend this kind of training to disaster management personnel in the country, municipalities and the public. The endresult would be to have all the user-community enlightened for optimum benefits to the country. Funding constraints have hindered the furthering of the project, though its future has been prioritised and it will continue in the short term, at least (Melton Mugeri, SAWS, pers. comm).

\section{RECOMMENDATIONS}

The role of forecasts, their production, dissemination and use as a tool to mitigate climate risk in South Africa has been outlined in this paper. In conclusion, a number of recommendations can be drawn from the material presented here. Firstly, it is evident that, above all, continued development and research into more accurate and usable seasonal climate forecasts must continue. Attention needs to be directed at intraseasonal variation such as onset, cessation and midseason dry spells. The temporal and spatial resolution of forecasts while not compromising on quality, need to be increased (Table 2).

It is also essential that a seasonal forecasting methodology include regular updates, assessments and ongoing user-education. 
Table 2. User requirements for an effective forecast (after Vogel 2000 and Klopper \& Bartman 2002)

Discussion process at SAWS
- Timing - there are critical times at which forecast infor-
mation is required
- Supplementary value-added information, e.g. crop
yield and maturity predictions
- Aim to advance adaptive capacity
- Comparisons with historical analogues
- Ongoing evaluation and updating
- Relate to traditional indicators
- Packaging
- Higher spatial resolution
- Climate scenario education
- Other technical support and information

Secondly, while it is clear that there is much scientific and government effort being devoted to the production of forecasts and their dissemination, this still remains a rather 'top-down' process. There is much work still be done on better understanding the clients whom one wants to engage around forecast use. We need to raise the profile of improved 'science' efforts to better understand the context and constraints within which users operate. Clear institutional roles, networks and accountability need to be identified, consolidated and maintained. The production of suitable forecasts is of minimal use if the means for effective and rapid interpretation and dissemination are lacking. Other recommendations include user requirements for an effective forecast identified by Vogel (2000) and Klopper \& Bartman (2002) (Table 1), as well as specific recommendations detailed below, including:

- End-users and their needs need to be better characterised such that their needs are built into the design and outreach of the forecast system,

- Key intermediaries, including those referred to above such as NDA-ARM (including civil society initiatives) need improved support and capacity building,

- Intermediary mechanisms such as the agricultural advisory need further development and extension to other climate-sensitive sectors (such as water, energy, health and disaster management),

- Forecasts that are 'tailored' or value-added such that they provide improved decision support for specific sectors and for specific commodities require research and development, something increasingly acknowledged by key players in the forecast system such as SAWS (Archer 2003, Vogel \& O'Brien 2003). It is clear that basic structures as well as demand for improved application of predictive climate products are in place in South Africa. At its best, such predictive information can be used as a tool to mitigate the negative effects of climate stress. We hope that analyses and reviews of the forecast system such as this one will aid in improving the ability of the system to fulfil such a role. The Intergovernmental Panel on Climate Change shows projections of increased climate variability (McCarthy et al. 2001). In Africa, future food security may be at increasing risk, with agriculture's ability to sustain food production potentially constrained: 'Grain yields are projected to decrease for many scenarios, diminishing food security, particularly in small food-importing countries (medium to high confidence)' (McCarthy et al. 2001, p. 14). The ability of the climate information system to mitigate negative effects of climate stress in the agricultural sector and beyond is likely to become more, rather than less, critical in the future.

Acknowledgements. The authors wish to thank the following institutions for their contributions and for permission to use information from their websites and publications: Drought Monitoring Centre, Harare; International Research Institute, New York; Enviro Vision, Bloemfontein; Institute of Soil, Climate and Water, Agricultural Research Council, Pretoria; South African Weather Service, Pretoria; Climate Systems Analysis Group, University of Cape Town.

\section{LITERATURE CITED}

Archer ERM (2003) Identifying underserved end-user groups in the provision of climate information. Bull Am Meteorol Soc 84:11

Barnett TP, Preisendorfer RW (1987) Origins and levels of monthly and seasonal forecast skill for United States air temperature determined by canonical correlation analysis. Mon Weather Rev 115:1825-1850

Barnston AG, Glantz MH, He Y (1999) Predictive skill of statistical and dynamical climate models in forecasts of SST during the 1997-98 El Niño episodes and the $1998 \mathrm{La}$ Niña onset. Bull Am Meteorol Soc 80:217-244

Bezuidenhout CN (2001) Proposed framework for operational crop forecasts in the South African sugar industry. Proc S Afr Sug Technol Ass Congress, Durban 75:215-216

Bezuidenhout CN, Singels A (2001) The use of simulation crop modelling to forecast sugarcane yield. Proceedings of the SASTA workshop on burn/harvest to crush delays and crop estimating. Mt. Edgecombe, South Africa, p 20-29

Blench R (1999) Seasonal climatic forecasting: Who can use it and how should it be disseminated? Natural Resource perspectives 47, Overseas Development Institute, London

Cane M (2000) Understanding and predicting the world's climate system. In: Hammer GL, Nicholls N, Mitchell C (eds) Applications of seasonal climate forecasting in agricultural and natural ecosystems - the Australian experience. Kluwer Academic, Dordrecht, p 29-50

Dilley M (2000) Reducing vulnerability to climate variability in Southern Africa: the growing role of climate information. Clim Change 45:63-73

Everingham YL, Muchow RC, Stone RC, Inman-Bamber NG, Singels A, Bezuidenhout CN (2002) Enhanced risk management and decision-making capability across the 
sugarcane industry value chain based on seasonal climate forecasts. Agric Syst 74:459-477

Farago T, Wilhite DA, Glantz MH (1997) A forecast is just a forecast: it's not a guarantee. Internet Journal For African Studies No 2, March 1997, University of Bradford, Bradford: www.bradford.ac.uk/research/ijas/ijasno2/farago.html

Goddard L, Graham NE (1999) The importance of the Indian Ocean for simulating rainfall anomalies over eastern and southern Africa. J Geophys Res 104:19099-19116

Goddard L, Mason SJ, Zebiak SE, Robelewski CF, Basher R, Cane MA (2001) Current approaches to seasonal to interannual climate predictions. Int J Climatol 21:1111-1152

Hammer GL, Holzworth DP, Stone RC (1996) The value of skill in seasonal climate forecasting to wheat crop management in north-eastern Australia. Aust J Agric Res 47: 717-737

Hammer GL, Hansen JW, Phillips JG, Mjelde JW, Hill H, Love A, Potgieter A (2001) Advances in application of climate prediction in agriculture. Agric Syst 70:515-553

Hudson J, Vogel C (2003) The use of seasonal forecasts by livestock farmers in South Africa. In: O'Brien K, Vogel C (eds) Coping with climate variability: the use of seasonal forecasts in Southern Africa: Chapter 1. Ashgate, Aldershot, p 75-96

Jones JW, Hansen JW, Royce FS, Messina CD (2000) Potential benefits of climate forecasting to agriculture. Agric Ecosyst Environ 82:169-184

Jury MR (1998) Statistical analyses and prediction of KwaZulu-Natal climate. Theor Appl Climatol 60:1-10

Jury MR, Valentine HR, Lutjeharms JRE (1993) Influence of the Agulhas Current on summer rainfall along the southeast coast of South Africa. J Appl Meteorol 32: 1282-1287

Jury MR, Parker BA, Pathack B (1999a) Climatic determinants and statistical prediction of tropical cyclone days in the SW Indian Ocean. J Clim 12:1738-1746

Jury MR, Mulenga HM, Mason J (1999b) Exploratory longrange models to estimate summer climate variability over southern Africa. J Clim 12:1892-1899

Klopper E (1999) The use of seasonal forecasts in South Africa during the 1997/98 rainfall season. Water SA 25:311-316

Klopper E, Bartman AG (2002) Forecasts and commercial agriculture: a survey of user needs in South Africa. In: O'Brien K, Vogel HC (eds) Coping with climate variability: the use of seasonal forecasts in Southern Africa, Chapter 10. Ashgate, Aldershot, p 170-182

Landman WA, Mason SJ (1999) Operational long-lead prediction of South African rainfall using canonical correlation analysis. Int J Climatol 19:1073-1090

Landman WA, Mason SJ (2001) Forecasts of near-global sea surface temperatures using canonical correlation analysis. J Clim 14:3819-3833

Landman WA, Tennant WJ (2000) Statistical downscaling of monthly forecasts. Int J Climatol 20:1521-1532

Landman WA, Mason SJ, Tyson PD, Tennant WJ (2001) Retroactive skill of multi-tiered forecasts of summer rainfall over southern Africa. Int J Climatol 21:1-19

Lindesay JA (1988) South African rainfall, the southern oscillation and a southern hemisphere semi-annual cycle. J Clim 8:17-30

Lindesay JA, Vogel CH (1990) Historical evidence for southern oscillation-Southern African rainfall relationships. Int J Climatol 10:679-689

Mason IB (1982) A model for assessment of weather forecasts. Aust Meteorol Mag 30:291-303

Mason SJ (1995) Sea-surface temperature-South African rainfall associations, 1910-1989. Int J Climatol 15:119-135
Mason SJ (2000) Definition of technical terms in forecast verification and examples of forecast verification scores. IRI Outreach Publication, Palisades, NY

Mason SJ, Goddard L (2001) Probabilistic precipitation anomalies associated with ENSO. Bull Am Meteorol Soc 82(4): 619-638

Mason SJ, Mimmack GM (1992) The use of bootstrap correlation coefficients in climatology. Theor Appl Climatol 45: $229-233$.

Mason SJ, Goddard L, Graham NE, Yulaeva E, Sun L, Arkin PA (1999) The IRI seasonal climate prediction system and the 1997/98 El Niño event. Bull Am Meteorol Soc 80: 1853-1873

McCarthy JJ, Canziani OF, Leary NA, Dokken DJ, White KS (eds) (2001) Climate change 2001: impacts, adaptation and vulnerability. Intergovernmental Panel on Climate Change, Cambridge University Press, Cambridge

McGlinchey MG (1999) Computer crop model applications: developments in Swaziland. Proc S Afr Technol Ass 73: $35-38$

Murphy AH (1997) Forecast verification. In: Katz RW, Murphy $\mathrm{AH}$ (eds) The economic value of weather and climate forecasts. Cambridge University Press, Cambridge

Nicholls N (2000) Opportunities to improve the use of seasonal climate forecasts. In: Hammer GL, Nicholls $N$, Mitchell C (eds) Applications of seasonal climate forecasting in agriculture and natural ecosystems - the Australian experience. Kluwer Academic, Dordrecht, p 309-328

Palmer TN, Anderson DLT (1994) The prospects for seasonal forecasting. Q J R Meteorol Soc 120:755-793

Plant S (2000) The relevance of seasonal climate forecasting to a rural producer. In: Hammer GL, Nicholls N, Mitchell C (eds) Applications of seasonal climate forecasting in agriculture and natural ecosystems - the Australian experience. Kluwer Academic, Dordrecht, p 23-28

Reason CJC (2001) Evidence for the influence of the Agulhas Current on regional atmospheric circulation patterns. J Clim 14:2769-2778

Reason CJ, Mulenga H (1999) Relationships between South African rainfall and SST anomalies in the southwestern Indian Ocean. Int J Climatol 19:1651-1673

Richard Y, Trzaska S, Rocou P, Roualt M (2000) Modification of the southern African rainfall variability/ENSO relationship since the late 1960s. Clim Dyn 16:883-895

Ropelewski CF, Halpert MS (1987) Global and regional scale precipitation patterns associated with the El Niño Southern Oscillation. Mon Weather Rev 115:1606-1626

Ropelewski CF, Halpert MS (1989) Precipitation patterns associated with the high index phase of the Southern Oscillation. J Clim 2:268-284

Ropelewski CF, Halpert MS (1996) Quantifying Southern Oscillation-precipitation relationships. J Clim 9:1043-1059

Rosenzweig C (2001) Impacts of the El Niño-southern oscillation on agriculture: guidelines for regional analysis. In: Rosenzweig C, Boote KJ, Hollinger S, Iglesias A, Phillips J (eds) Impacts of El Niño and climate variability on agriculture. ASA Special Publication 63, American Society of Agronomy, Madison, WI, p 21-30

SADC-DMC (2002) Report of the 6th Southern Africa regional climate outlook forum. Harare, 4-6 September 2002. SADC Drought Monitoring Centre, Harare

Singels A, Bezuidenhout CN (1999) The relationship between ENSO and rainfall and yield in the South African sugar industry. S Afr J Plant Soil 16(2):96-101

Singels A, Donaldson RA (2000) A simple model for unstressed sugarcane canopy development. Proc S Afr Sugar Technol Ass Congress, Durban 74:151-154 
Stanski HR, Wilson LJ, Burrows WR (1989) Survey of common verification methods in meteorology. World Weather Watch Tech. Rept. No. 8, WMO/TD No. 358, WMO, Geneva

Stern PC, Easterling WE (eds) (1999) Making climate forecasts matter. National Academy Press, Washington, DC

Tennant WJ (1999) Numerical forecasting of monthly climate in southern Africa. Int J Climatol 19:1319-1336

Tennant WJ (2003) An assessment of intra-seasonal variability from 13-year GCM simulations. Mon Weather Rev 131:1975-1991

Vogel C, O'Brien K (2003) Climate forecasts in southern Africa. In: O'Brien K, Vogel C (eds) Coping with climate variability: the use of seasonal forecasts in southern Africa. Chapter 1. Ashgate, Aldershot, p 75-96

Von Storch H, Navarra A (eds) (1995) Analysis of climate variability. Application of statistical techniques. SpringerVerlag, Berlin

Walker S, Mukhala E, van den Berg WJ, Manley CR (2001)

Editorial responsibility: Otto Kinne, Oldendorf/Luhe, Germany
Assessment of communication and use of climatic outlooks and development of scenarios to promote food security in the Free State Province of South Africa, Final report submitted to the Drought Monitoring Centre (Harare-Zimbabwe, Univ of Free State and Enviro Vision)

Washington R, Downing TE (1999) Seasonal forecasting of African rainfall: prediction, responses and household food security. Geogr J 165:255-274

WHO (2001) Malaria early warning systems: concepts, indicators and partners; a framework for field research in Africa. Roll Back Malaria Cabinet Project, World Health Organization. WHO, Geneva

Ziervogel G (2004) Targeting seasonal climate forecasts for integration into household level decisions: the case of smallholder farmers in Lesotho. Geogr J 170.1:6-21

Ziervogel G, Calder R (2003) Climate variability and rural livelihoods: assessing the impact of seasonal climate forecasts. Area 35(4):403-417

Submitted: December 16, 2003; Accepted: November 4, 2004 Proofs received from author(s): December 10, 2004 